\title{
La democracia como procedimiento y como régimen
}

- Comelius Castoriadis*

El objeto de nuestra discusión traduce y expresal la crisis que aclualmente atraviesa el movimiento democrático. I a elección de semejante tema fla estralegia democrátical está condicionada, precisamente, por la aparición de una concepción de la "democracia" que la reduce a un simple conjunto de "procedimientos", rompiendo así con todo el pensamiento polílico precedente, que veía en la democracia un régimen político, indisociable de una concepción sustantiva de los fines de la institución política y de una visión sobre el lipo de ser humano que le corresponde. Se ve fácilmente que, independientemente de cual sea el ropaje filosófico con el que se cubra, una concepción meramente procedimental de la "democracia" tiene su propio origen en la crisis de las signilicaciones imaginarias que se refieren a las finalidades de la vida colectiva, y prelende ocultar esta crisis disociando la "forma del régimen político" de cualquier discusión relativa a esas finalidades, o incluso llegando a suprimir la idea misma de éstas. El profundo vínculo que une esta concepción con lo que se hallamado, más bien irrisoriamente, el individualismo contemporáneo, es algo manifiesto y volveré sobre ello. Pero conviene comenzar por el principio.

\section{I}

Discutir sobre la democracia significa discutir sobre la polílica. Ahora bien, la política no existe siempre y en cualquier lugar; la verdadera política es la

* Publicado en Iniciativa Socialista, n" 38, fehrero 1996. Cornclius Castoriadis, de la École des hautes études en sciences sociales de Paris, es uno de los mas importantes pensadores contemporáneos. Este texto recoge su intervención e'n el encucentro internacional "La estrategia democrática". celehrado e'n Roma, en felbrero de 190)4. cuyas ponencias fueron recogidas en el libro La strategia democrática nella sociela che cambia, Ed. Datanews, Roma, mayo de 190.5.

Lo democraclo como procedimlento y como régimen 
resultante de una creación histórico-social rara y frágil. Lo (que existe en loda sociedad es el político: la dimensión -explicila, implicila o cuizá casi imperceptible- que tiene que ver con el poder, esto es, la instancia o las inslancias instituidas, que pueden emitir mandatos con autoridad, y que, al menos, deben incluir siempre, de forma explicita, lo que denominamos un poder judicial y un poder de gobierno'. Pueden existir, ha habido y acuí se augura que habrá de nuevo, sociedades sin Estado, carentes de un aparato hurocrílico jerírpuicamente organizado, separado de la sociedad y en posición de dominio respecto a ésta. I:I Estado es una creación histórica fechable y localizable: Mesopotamia, Isste y Sudeste asiáticos, la Centroamérica precolombina. Una sociedad sin tal listado es posible, concebible, augurable. Pero una sociedad sin instituciones explicitas de poder es un absurdo, en el (jue cayeron Marx y los anarguistas.

No hay ser humano extrasocial; no existe ni la realidad ni la licción coherente de un "individuo" humano como sustancia asocial. extrasocial o presocial. No podemos concebir un individuo sin lenguaje, por ejemplo, y no existe lenguaje más que como creación e institución social. Ista creación y esta instilución no pueden ser vistas, a menos de caer en el ridiculo, como resultado de una cooperación consciente de "individuos", ni tampoco de una suma de redes "intersubjetivas": para (que haya intersubjelividad es necesario clue haya sujelos humanos y la posibilidad de que se comunicuen. Iin otras palabras. dehe haber seres humanos ya socializados y un lenguaje que no podrian producir ellos mismos como individuos (uno o muchos: "redes intersubjetivas"), sino (jue reciben necesariamente de su socialización. I a misma consideracion puede aplicarse a mil aspectos diversos de eso pue se llama individuo. I a "lilosolía politica" contemporánea -como lambién el núcleo de lo cue pasa por ser ciencia economica- está fundada sobre esta licción incoherente de un individuo-sustancia, hien definido en sus determinaciones esenciales, luera o frente a toda sociedad: sobre este absurdo se apoyan necesariamente la idea de la democracia como simple "procedimiento" y el psecudoindividualismo contemporáneo. Pero luera de la sociedad el ser humano no es ni hestia ni Dios (Arislofeles), pues simplemente no es, no puede existir, ni lísicamente ni, sobre todo, psicpuicamente. I:l hopeful and dreadful monster |monsiruo promeledor y terrible| (jue es el neonalo humano, radicalmente inadaplado para la vida, debe ser humanizado, y esta humanización es su socialización, trabajo social mediado e instrumentado por el ambiente inmediato del infante. El ser-sociedad de la sociedad son las instituciones y las significaciones imaginarias sociales (pue esas instituciones encarnan y hacen existir en la efectividad social. Istas significaciones son lo que da un sentido - sentido imaginario, en la acepción profunda del lérmino, esto es, creación espontánea e inmolivada de la humanidad- a la vida, a la aclividad, a las decisiones, a la muerte de los seres humanos, como lambién al mundo que crean y en el que los seres humanos deben vivir y morir. La polaridad no esta entre individuo y sociedad - pues el individuo es un fragmento de la sociedad y al 
mismo liempo una minialura suya, o, mejor dicho, una especie de holograma del mundo social-, sino entre psique y sociedad. la psicjue dele ser, mejor o peor, domada, debe aceplar una "realidad" que le es helerogénea y extraina al principio, y, en cierlo sentido, lambién hasta el linal. Esia "realidall" y su aceplación son obra de la instilución. Issto lo supieron los griegos: los modernos, en gran parle a causa del cristianismo, lo han oculado.

La instilución - y las significaciones imaginarias que ella expresa- no pue(le existir si no se conserva, si no se alapla para sobrevivir: la laulologia darwiniana encuentra acpui un fecundo lerreno de aplicación. $\Lambda$ simismo, se conserva gracias al poder, y este poder existe ante lodo como inlrapoder radical. siempre implícilo. Se puede haher nacido en Ilalia en 194.5. en Francia en 1930, en Estados Unidos en 194.5, en (irecia en 1922. No lo hemos decidiclo, pero este hecho decide la parle esencial de cadla existencia: nuestra propia lengua, nuestra propia religión, el (o)\%, (en el mejor de los casos) del propio pensamiento, actuello por lo que se desea vivir o se acepla (o no se acepla) morir. Isto es mucho mis, y cosal muy distinta, (que el simple "estar en el mundo" (jue no se ha elegido (la (ieworfenheit de Ileidegger). Isste mundo no es un mundo o el mundo tout court, es un mundo histórico social, lormado por la institucion, cyue contiene en modo indescriptible innumerables consecuencias de la historia precerlente.

Descle su nacimiento, el sujelo humano (pueda cogido en un campo histórico social, y es colocado simultaneamente hajo la influencia del imaginario colectivo instituyente, de la sociedad instituida y de la historia de la cue dicha instilución es su cumplimiento provisional. I a sociedad no puede dejar de producir, en primer lugar, individuos sociales conformes a ella y fue la producen a su ve\%. Incluso si se nace en una sociedad conflictiva, el terreno del conflicto, la puesta en juego y las opciones estin predelerminadas; incluso si se va a llegar a ser lïósofo, será esta historia de esta lilosolïa, y no otra, la (pue constituiri el punto de parlicla de la reflexión. Listo se encuentra mucho mais acii, o mais allia, de foda intención, voluntad, maniobra, conspiración, disposición de cualcuier instilución. ley, grupo o clase delerminadas.

Al lado, o "por encima", de esile inlra-poder implicito, siempre ha hahiclo y siempre habrai un poder explicilo, instifuido como tal, con sus dispositivos particulares, con su funcionamiento definido y con las sanciones legitimas (jue puede aplicar". La necesidad de existencia de lal poder deriva al menos de cuatro faclores:

(a) El mundo "pre-social" en cuanto lal amenaza siempre el sentido instaurado de la socieclad; (b) La psique de cadla ser humano no estia ni puede estar nunca completamente socializada ni ser tolalmente conforme a lo cue las instiluciones le exigen; (c) La sociedad contiene siempre, en su instilución y en sus significaciones imaginarias, un impulso hacia el porvenir, y el porvenir excluye una

La democracio como procedimiento y como régimen 
codificación (o una mecanización) preliminar y exhaustiva de las decisiones a tomar. De ello deriva la necesidad de instancias explícitamente instituidas sobre la base de sla posibilidad de tomar decisiones autorizadas sobre lo que hay que hacer y lo que no hay que hacer, esto es, sobre la base de la posibilidad de legislar, "Ilevar a cabo", resolver los litigios y gobernar. Las primeras dos lunciones pueden estar ocultas en la estructura consuctudinaria del sistema normalivo (y lo han estado, en la mayor parte de las sociedades arcaicas), pero no puede decirse lo mismo de las dos últimas. Por último, y sobre lodo, este poder explicilo es el garante instituido del monopolio de las significaciones legílimas en la socicdad considerada.

Lo político es todo aquello que concierne a este poder explicito (los modos de acceso a él, el modo apropiado de gestionarlo, etc.)

Este lipo de institución cubre la casi totalidad de la historia humana. Así ocurre en las sociedades heterónomas: crean ciertamente sus propias instituciones y significaciones, pero ocultan esta autocreación, impulándola a una fuente extrasocial - los antepasados, los héroes, los dioses, Dios, las leyes de la historia o las leyes del mercado-, en todo caso, una fuente exterior a la efectiva actividad de la colectividad efectivamente existente. En lales sociedades heterónomas, la institución de la sociedad liene lugar en el cierre del sentido. Todas las preguntas formulables en la sociedad considerada pueden encontrar respuesta en las significaciones imaginarias, mientras que las que no pueden hacerlo son, más que prohibidas, imposibles mental y psíquicamente para los miembros de la sociedad.

Esta situación, por lo que sabemos, sólo ha sido rola dos veees en la historia: en la Grecia antigua y en Europa occidental. Y de esa ruplura somos herederos, es ella la que nos permite hablar como hablamos. La ruptura se expresa a través de la creación de la política y de la filosofía (de la reflexión). Política: puesta en cuestión de las instituciones establecidas. Filosofía: puesta en cuestión de los idola tribus, de las representaciones comúnmente aceptadas.

En estas sociedades, el cierre del sentido se rompe, o por lo menos tiende a romperse. Esa ruptura $\rightarrow$ la actividad de interrogación incesante' que la acosnpaña-implica el rechazo de una fuente de sintido diferente a la actividad viva de los seres humanos. Implica, por tanto, la repulsa de toda "autoridad" "quce no rinda cuenta y razón, y que no justifique la validez del derecho de sus ('munciados. De ello se derivan de forma casi inmediata:

(a) La obligación de todos de dar cuenta y razón (logon didonai) de los propios actos y de las propias afirmaciones. (b) La repulsa de las "diferencias" o "alteridades" (jerarquía) preliminares en las posiciones respectivas de los individuos y, consiguientemente, la puesta en cuestión de todo poder que dé lugar a ellas; (c) La apertura de la pregunta sobre las buenas (o mejores) instituciones, 
en la medida en que dependen de la aclividad consciente y explícila de la coleclividad; y, por lanto, lambién la aperlura de la pregunla sobre la justicia. Se nota fácilmente que estas consecuencias conducen a considerar la politica como una larea que alecta a todos los miembros de la colectividad respecliva, una larea que presupone la igualdad de lodos y tralla de hacerla electiva. Una tarea, pues, que lambién es de transformación de las instituciones en el sentido de la democracia. Podemos ahora definir la politica como la aclividad explicila y lúcida que concierne a la inslaturación de las instiluciones deseables, y la democracia como el régimen de autoinstitución explicila y lúcida, lanto como es posible de instiluciones sociales que dependen de una aclividad colectiva y explicita.

Casi no haria falta aniadir que esta autoinstitución es un movimiento incontenible, que no prelende lograr una "sociedad perlecta" (expresión carente de sentido), sino una sociedad libre y jusla, en la medida de la posible. 1 esice movimiento le llamamos el proyecto de una sociedad autonoma y. llevado a su cumplimiento, debe establecer una sociedad democratica.

Surge una pregunta preliminar, ya planteada eleclivamente en la historia: ¿por qué se quiere, por (pue se debe (puerer, un régimen democrítico? No lo disculiré aquí, limilándome a observar (jue esal pregunta implical yal (jue debemos (o deberiamos) vivir en un régimen en el que todas las pregunlas pueden ser planteadas, y eso también es el régimen democrálico.

Asimismo, es inmedialo (que semejante instilucion, en la (pue lodas las pre gunlas pueden ser planteadas, donde ninguna posición ni s/alus estan delerminados o garantizados de parlida, deline la democracia como régimen. Volveré sobre ello.

Se ha objelado que esta visión comporla una concepción sustantiva de la felicidad de los ciudadanos y que, por lanto, desemboca fatalmente en el totalilarismo (posición explicitamente expresada por Isaliah IBerlin e implicila en las argumentaciones de Rawls o llabermas)!

Pero nada de lo dicho hasla ahora alude a la "felicidad" de los ciudadanos. Se pueden comprender las razones historicals de lales objeciones, desde el lamoso "la felicidad es una idea nueva en turopa" de Salint Just hasta la monsiruosa farsa de los regímenes estalinistas, que precendian trabajar por -y realizar- la felicidad del pueblo ("La vida se ha hecho mejor, compañeros. La vida se ha hecho más feliz", declaraba Stalin en el apogeo de la miseria y del terror en Rusia). Pero estas motivaciones no bastan para justificar la posición teórica, que parece una reacción casi epidérmical a una situación histórical de colosiales dimensiones - la emersión del totalitarismo- que exigía un análisis mucho más profundo de la cuestión política. El objetivo de la política no es la felicidad, sino

Lo democrocio como procedimiento y como régimen 
la libertad. La libertad efectiva (no me refiero aquí a la libertad "filosófica") es lo que Ilamo autonomía. La autonomía de la colectividad, que no puede realizarse más que a través de la autoinslitución y el autogobierno explicilos, es inconcebible sin la autonomía efectiva de los individuos que la componen. Lal sociedad concreta, que vive y funciona, no es otra cosa que los individuos concretos, ef ectivos, "reales".

Pero lo inverso es igualmente cierto: la autonomía de los indivicluos es inconcebible sin la autonomía de la colectividad. En realidad, iqué significa, cómo es posible, qué presupone la autonomía cle los individuos? ¿Cómo se puede ser libre si se está colocado obligaloriamente bajo la ley social?" Existe una primera condición: es necesario que se tenga la posibilidad efectiva de participar en la formación de la ley (de la institución). No se puecle ser libre bajo una ley si no se puede decir que esa ley es propia, si no se ha teniclo la posibilidad efectiva de participar en su formación y en su instilución (incluso cuando las preferencias propias no han prevalecido). En vista de que la ley es necesariamente universal en su contenido y, en una democracia, es colectiva en su fuente (punto cue, en teoria, no discuten los procedimenlalistas), de ahi se deriva que la autonomía (la libertad) efectiva de todos, en una democracia, debe ser una preocupación fundamental de cada uno (el "olvido" de esta evidencia es una de las innumerables estafas (lel pseudo "individualismo" contemporáneo), ya que la cualidad de la colectividad que adopta decisiones que nos afectan es algo que nos interesa de manera vital (en otro caso, nuestra propia liberlad se convierle en algo polílicamente irrelevante, estoica o ascélica). Tengo un inlerés positivo lundamental (y lambién egoista) en vivir en una sociedad mais cercana a la del Simposio (jue a la de $1:$ I Padrino o a la de Dallas. L a propia libertad, en su realización electiva, es función de la libertad efectiva de los otros. Idea ésta (que, ciertamente, es incomprensible para un carlesiano o para un kantiano.

No hay ninguna duda de que el despliegue y la realización de esta liberlad presupone algunas disposiciones instilucionales precisas, incluidas algunas disposiciones "formales" y "procedimentales": Ios derechos individuales (Bill of Rights), las garantias judiciales (duc processs of lan; mullum crimen, mulla porna sine lege), la separación de poderes, etc. Pero las liherlades a las que dan resullado son estrechamente delensivas (negalivas). Todas estas clisposiciones presuponen -y se Irata del postulado lácilo calsi general en lo que pasal por ser filosofía polílica moderna- que haya ahi delante un poder extraño a la colectividad, inamovible, inalacable, por esencia hostil y peligroso, cuya polencia se pretende limitar en la medida que sea posible. Reencontramos así la filosolía tácila de los comunes ingleses respecto al monarca, y la posición explicila de los textos fundadores de la Constitución americana. El hecho de que algunos siglos más larde, los "pensadores polílicos" de la modernidad se comporlen psícuica e intelectualmente como "servidores sumisos y obedientes de vuestra Excelencia" -Eu. Excellenz untertaenig gehorsamster Diener"- sorprendera solamente a 
quienes no hayan reflexionado nunca sobre la exiraña relación entre la mayor parte de los intelecluales y los poderes establecidos'.

Libertad bajo la ley —autonomia- significa participación en el posicionamiento de la ley. Es una tautología afirmar que esta participación sólo realiza la libertad cuando ella es igualmente posible para lodos, no en la lelra de la ley sino en la efectividad social. De eso se deriva inmedialamenle lo ahsurdo de la oposición entre igualdad y libertad, repetida a lo largo de varios decenios. $\wedge$ menos que se las tome en acepciones lolalmente engariosas, las dos nociones se implican reciprocamenten. I a igual posibilidad efectiva de parlicipalcion comporla el reconocimiento efectivo de las condiciones de lodo orden paral esta parlicipación. Ias implicaciones son maniliestamenle inmensals y aharcan una parte considerable de la inslitución global de la sociedad; pero el punto de apoyo arquimédico es evidentemente la paidera feducación| en su sentido mais profiundo y duradero, sobre el (pue lormare.

Por consiguiente, no es posible realizar una "democracia procedimental" que no sea un fraude, si no se inlerviene profundamente sobre la organizacioun de la vida social.

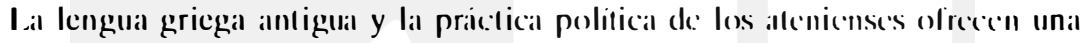
distinción preciosal ---y, en mi opinion, de valide. universal entre tres esterals de la aclividad humana, gue, a su ve\%, la insilucion global de la sociedald debe

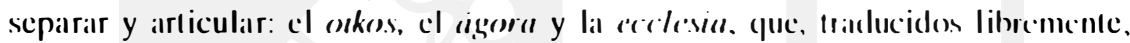
serian la estera privada, la estera privalda/priblical y la esleral formalmente y en sentido luerte) públical, (que correspemelerial con lo (que mis arribal le definido

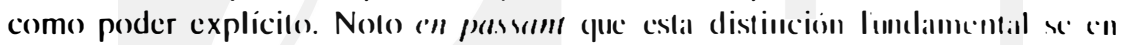
cuentral en los hechos y en el lenguaje. pero no lue expliciladal con tales firminos en la épocal clasica, ni lampoco por el pensador clasico de la democracia, Aristóleles, exceplo parcialmente. Isstas esteras no son nelamente distintas (y precisamente arliculadias) salvo en un rigimen democrilico. Bajo un rigimen tolalitario, por ejemplo, la eslera piblical ahsorbe cualcpuice cosia, y, al mismo liempo. en realidad no es publicä en ahsolulo, pues constiluye la propicedald del

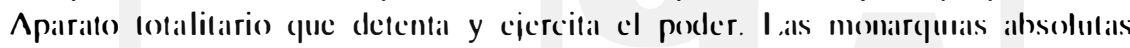
Iradicionales respelahan, en leoria, la independencial de la esteral privalda, del oikes, y sólo intervenian moderadamenle en la estera privada/puihlical, el angeral Paradójicamente, las pseudo "democracias" occidentales comtemporinteals, de he cho, han transformado, en gran medida, la esferal públical en priviada: lass decisiones verdaderamente importantes se tomaln en secreto y tras los hastidores (del Gobierno, del Parlamento, de los aparaltos de los parlidos). Se puede dar unal definición de democracia tan huena como cualquier otral la democracial e's el régimen en el que la esfera publica se hace verdadera y efectivamente publical, perlenece a lodos, está electivamente ahierla a la participacion de todos.

Lo democrocio como procedimiento y como régimen 
El oikos, la casa-familia, la esfera privada, es el campo en el que, formalmente y como principio, el poder ni puede y ni debe intervenir, aunque, como es usual en este campo, eso ni puede y ni debe entenderse en sentido absoluto: la ley penal prohibe atentar contra la vida o la integridad física de los micmbros de la propia familia, la enseñanza de los niños se ha hecho obligatoria incluso bajo los gobiemos más conservadores, etc.

El agora, el mercado-lugar de reunión, es el campo en el que los individuos se encuentran libremente, discuten, contratan recíprocamente, publican y compran libros, etc. Tampoco aqui, formalmente y como principio, puede ni debe intervenir el poder, aunque tampoco puede entenderse eso en sentido absoluto. La ley impone el respeto de los contratos privados, prohibe el trabajo de los niños, etc. En realidad, nunca acabaríamos de enumerar los puntos sobre los que el poder, también en los Estados más “liberales" (en el sentido del liberalismo capitalista), intervienc en este campo (un cjemplo que se pondrá después: el Presupuesto), ni tampoco las disposiciones a través de las que lo hace.

La ecclesia, termino aquí utilizado metafóricamente? es el lugar del poder, el campo público/público. El poder incluye a los poderes, y éstos, a su vez. deben estar separados y articulados. Me remito a otros textos donde he tratado más ampliamente el tema ${ }^{x}$ y me limilaré ahora a algunos puntos relevantes para la presente discusión.

Si se considera concretamente la actividad de las diferentes ramas del poder, está claro que no existe un campo en el que se puedan asumir y adoptar decisiones sin tomar en consideración apreciaciones sustanciales. I o que vale tanto para la legislación como para el gobicrno, para el "cjecutivo" como para el judicial.

De hecho, es imposible imaginar una ley --exeepción hecha, parlicularmentc, de las leyes de procedimiento- que no decida sobre cuestiones sustantivas. Ni la prohibición de homicidio queda excluida, como testimonian las múlliples restricciones, excepciones y cualificaciones de que está rodeada, siempre y en $10-$ das parles. Lo mismo puede decirse sobre la "aplicación" de estas leyes, lanto desde el judicial como desde el "ejeculivo"”. El juez no puede (y, en lodo caso, no debe) ser nunca un Paragraphen/automat, porque se encuentra siempre con los "vacíos del derecho" (Re'hts/ucke'n), pero sobre todo porque siempre hay un problema de interprelación de la ley y, más profundamente, un problema de equidad"'. Tanto la interpretación como la equidad son inconcebibles sin recurrir e invocar al "espírilu del legislador", y lo mismo ocurre con sus "intenciones" y los valores sustantivos hacia los que se supone que este úllimo mira. Las cosas se plantean de la misma forma respecto a la administración, en la medida que ćsta última no podría "aplicar" las leyes y los decrelos sin interpretarlos. Y lo mismo puede decirse, en el máximo grado posible, sobre el Gobierno. La función de gobierno es "arbitraria". Se desenvuelve en el mareo de la ley y está 
vinculada a la ley (esto se refiere evidentemente a lo que se considera cl caso de los regímenes "democráticos" occidentales), pero no aplica ni cumplimenta, por lo común, las leyes. La ley (en general, la Constitución) eslablece que el Gobierno debe presentar cada año un proyecto de presupuestos ante el Parlamento, y que éste (compartiendo en este caso una función de gobicrno y no "Icgislativa") debe expresar su voto, con o sin enmiendas al texto original; lo que la ley no dice, y no podría nunca decir, es qué debe haber dentro de dicho Presupuesto. Es totalmente evidente que es imposible imaginar un Presupuesto que no esté imbuido de cabo a rabo, tanto para los ingresos como para los gasios, por decisiones sustantivas inspiradas en ciertos objetivos y en cierlos "valores" hacia cuya realización apunta. Más en general, todas las decisiones no banales de gohierno afectan y vinculan el fuluro, en una oscuridad radical y radicalmente inevilable. Tienden a orientar la evolución de la sociedad, en la medida en que ésta depende de ellas, en una dirección que se prefiere a olra. ¿Cómo podrían acometerse tales decisiones sin apelar, aunque sea laicilamente, a opciones sustantivas?

Podría aducirse que hien podria darse que lodas estas decisiones explicitas (parlicularmente las legislativas y de gobierno) sólo apunlasen a la conservación del eslado de cosas exisiente, o a la preservación de la liberlad de la sociedad (no "política") para hacer emerger de sí misma y desplegar las "formas de vida suslancial" que le son gralas. Pero esie argumento contiene, aunque sea implícitamente, una aserción de valoración posiliva de las formas y de los contenidos ya existentes de la vida social, ya sean herencia de liempos inmemoriales, ya sean producto de la aclividad contemporánea de la sociedad. Para poner un ejemplo familiar al leclor de hoy, el "liberalismo" extremo remile a una alirmación de suslancia: aquello que "Ios mecanismos del mercado" o la "libre inicialiva económica", elc., producen, es "bueno" o "el menor mal posible", o bien dice que ningún juicio de valor sobre ello ser expresado (las dos alirmaciones, evidentemente contradiclorias, han sido sostenidas simultínea o sucesivamente por F. von Hayck, por ejemplo). Alirmar que ningún juicio de valor puede ser expresado sobre aquello que la sociedad "espontíncamente" produce, impele hacia el nihilismo histórico lotal y termina afirmando, por ejemplo, que cualquier régimen (estalinista, nazi u otro) equivale a cualquier otro. C'onsiderar que lodo aquello que la Iradición o, lo que es lo mismo, la sociedad, produce esponláneamente es bueno o el menor mal posible fuerza a lralar de demosirar, en cada caso y en cada ejemplo preciso, porque eso sería asi y, por lanlo, fueraa a entrar en una discusión sustanliva.

Ya que nadie en posesión de sus facultades mentales podría rechazar estas constataciones, la duplicidad del punto de vista procedimental se hace clara: no se trata de negar que las decisiones que implican cuestiones de sustancia deban ser tomadas, sea cual sea el lipo de régimen considerado, sino de alirmar que, en un régimen "democrálico". solamente son relevantes la "lorma" o el "procedi-

La democracio como procedimiento y como régimen 
miento" para la toma de esas decisiones, es decir, que esta "forma" o este "procedimiento" por sí mismos caracterizan un régimen "democrálico".

Con todo, admitamos que las cosals sean así. Pero todo "procedimiento" debe ser aplicado por seres humanos. Seres humanos que deben poder, deber y estar obligados a aplicar este procedimiento según su "espírilu". ¿Pero quiénes son estos seres humanos, de dónde vienen? Essa pregunta sólo se podría eludir desde la ilusión metafísica del individuo-sustancia, preformado en sus determinaciones esenciales, para el que su pertenencia a un ambiente histórico-social definido sería accidental, como lo sería el color de los ojos, postulando así la existencia efectiva (que se encuentra en la polílica efecliva, no en las ficciones "contrafactuales"), la existencia de átomos humanos - ya dotados no sólo de "derechos", etc., sino de una conciencia perfecla de las disposiciones del derecho (sin la que sería necesario legitimar una división del Irabajo establecida de una vez. por todas entre "simples ciudadanos" y jueces, administradores, legisladores, etc.)- que tenderían por sí mismos, includible e independientemente de loda formación, historia personal, etc., a comporlarse como álomos jurídico-polílicos. Esta ficción del homo juridicus es lan ridicula e inconsistente como la del homo) aconomicus, y ambas presuponen la misma melafísica antropológica.

Para el punto de vista procedimental, los seres humanos (o una parte suliciente de ellos) deberian ser puros entendimientos jurídicos. Pero los individuos efectivos son otra cosa muy distinta. Estamos obligados a lomarles como vicnen, forjados ya por la sociedad, con su historia, sus pasiones, sus multiples pertenencias particulares, tal y como han sido consiruidos en el proceso historico-social y en la institución dada de la sociedad. Porque seríamos diversos, sería necesario que esta institución, en los aspeclos sustanciales y sustanlivos. fuese diversa. Incluso si suponemos una democracia calida del ciclo, tan completa y perfecta como se quiera, esia democracia no podría durar más que algunos años a menos que produzca los individuos que le corresponden y que son, ante todo y sobre todo, capaces de hacerla funcionar y de reproducirla. No puede haber sociedad democrática sin paideia democráticia.

La concepción procedimental, salvo caer en la incoherencia. eslii obligada a introducir subrepticiamente --o llevar hasta - al menos dos juicios de sustancia y de hecho:

(a) Las instituciones electivas, dadas, de la socicdad son, lal y como son. compatibles con el funcionamiento de procedimientos "verdaderamente" democráticos; (b) los individuos, lal como son consiruidos por esla sociedad, pueden hacer funcionar los procedimientos establecidos en su "espírilu" y defenderlos. Estos juicios tiene múltiples presuposiciones y comporlan numerosas consecuencias. Mencionemos dos. La primera es que nos encontramos nuevamente con la cuestión fundamental de la equidad, no en el sentido sustanlivo, sino ante lodo en el sentido estrechamente lógico ya establecido por Plalón y Aristólcles': Hay 
siempre inadecuación entre la maleria a juzgar y la forma misma de la ley, pues la primera es necesariamente concrela y especilica y la segunda es abstracta y universal. Esta inadecuación no puede ser colmala más (jue con el trabajo crealdor del juez "que se pone en el puesto del legislador", lo gue implica que lome en cuenta consideraciones sustantivas. Todo esto va mucho mís allá del proceclimentalismo.

La segunda es que, para que los individuos sean capaces de hacer funcionar los procedimientos democrálicos según su "espirilu", es necesario que una parle imporlante del trabijo de la sociedal y de sus instiluciones se dirija hacia la producción de individuos gue se correspondan eon esta delinición, esto es, mujeres y hombres democrálicos lambién en el sentido estrechamente procedimental del lérmino. Pero entonees es preciso afrontar el dilema siguiente: o estat educación de los individuos es dogmálica, autorilaria, heterónomal --y la predensión democrálica se convierte en el expuivalente polílico de un rilual religioso-: o hien, los individuos que dehen "aplicar el procedimiento" - volar, legislar. seguir las leyes, gobernar- han sido educados de manera crílica. In lal caso, es necesario que este espírilu crilico sea valorizado, en cuanto lal. por la inslilución de la sociedad, y entonees se abre la caja de Pandora de la puesta en cuestión de las instituciones existentes. y la democracia vaclve a ser movimiento de auloinstifución de la sociedad, esto es, un nuevo lipo de régimen en el sentido pleno del término.

Ios periodistas y lambién algunos likosolos polílicos que parecen ignorar totalmente las largas dispulas de la "libosolia del derecho" de los dos áltimos siglos, hablan constantemente del "Isstado de derecho". Pero si el "Istado de

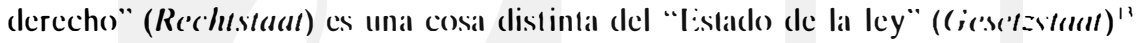
no es sino porque aquel va más alla de la simple conformidad con "procedimientos", planteando la cuestion de la justicia e implicando incluso a las reglas juridicas ya existentes. Pero la cuestión de la juslicia es la cuesticon de la politica, de cuándo la instilución de la sociedad ha dejado de ser sagrada o Iradlicional. Desede entonces, el "reino de la ley" no puecle eludir la pregunta iqué ley, por qué esta ley y no otra" Ni sicpuicra la respuesta "lormalmente democrailica" -la ley es ley porque representa la decisión de mayoría (omilimos evidentemente el saber si realmente lo es)- impide la pregunta: i.y por (ué debe ser asi" Si la justilicación de la regla de la mayoria es estrechamente "procedimental" - por ejemplo, porque es necesario cue loda discusión lenga lérmino--, entonces cualquier regla poelria lener la misma justilicacions: sortear la decision, por ejemplo. La regla mayoritaria no puede ser justilicalda si no se adtmite el valor igual, en el campo de lo contingente y lo probable, de las doxai fopiniones/ de individuos libres". Pero si este igual valor no clebe cuedarse reducido a un "principio contrafactual", un engano pseudotrascendental, entoneses es larea permanente de la instilución de la sociedad producir individuos de los cue puede posstularse

La democracia como procedimiento y como régimen 
razonablemente que sus opiniones lienen el mismo peso en el campo político. Una vez más, la cuestión de la paideia se revela ineliminable.

La idea de que el "derecho positivo" y sus procedimientos puedan separarse de los valores sustantivos es un espejismo. También lo es la idea de que un régimen democrático podría recibir de la historia, ready-made [confeccionados], individuos democráticos que le harían funcionar. Tales individuos sólo pueden ser formados dentro, y a través, de una paideia democrálica, que no brota como una planta sino que debe ser un objeto central de las preocupaciones politicas.

Los procedimientos democrálicos constituyen una parle, cierlamente importante, pero sólo una parte, de un régimen democrálico. Y deben ser verdaderamente democráticos, en su espíritu. En el primer régimen que se puede llamar, a pesar de todo, democrático, el régimen aleniense, lueron inslituidos no como simples "medios", sino como momento de encarnación y de la facilitación de los procesos que lo realizaban. La rotación, el sorteo, la decisión tras la deliberación de todo el cuerpo político, las elecciones y los tribunales populares, no se basahan tanto sobre el postulado de la igual capacidad de lodos para asumir las cargas públicas, sino más bien constituian las piezas (le un proceso polílico educalivo, de una paideia acliva, que pretendia ejercilar y lambién desarrollar entre ellos todas las capacidades correspondientes, y, por lanto, hacer el postulado de la igualdad política tanto más posible por estar más próximo a la realidad efecliva.

\section{IV}

En verdad, las raices de estas confusiones no son solamente "ideales", en el sentido de que no deben ser huscadas esencialmente o exclusivamente en "falsals ideas", en la misma medida en que no son solamente "materiales". en el sentido de que no deben entenderse como mera expresión, más o menos consciente, de intereses, pulsiones, posiciones sociales, etc. Se apoyan sohre el imaginario histórico-social de la edad "política" moderna, desde su prehistoria, pero ante todo sobre su carácter antinómico. Ahora no es posible dedicarse a hacer una dilucidación de esto, así que me limitaré al intento de seleccionar algunos puntos relevantes de la constelación de ideas en cuyo interior y a través de las cuales se ha expresado este imaginario en la esfera política. Comenzaré in média res. Es conocida la crítica habitual que el marxismo dirigia a los derechos y a las lihertades "burguesas" (y que se remonta, sea lo que quiera que se diga, a Marx mismo): se tratarian de libertades y derechos simplemente "formales", establecidos más o menos en interés del capitalismo. Crítica incorrecta por muchas razones. Estos derechos y libertades no han nacido con el capilalismo ni han sido reconocidos por él. Reivindicados inicialmente por la protohurguesía de las comunas desde el siglo $X$, han sido arranciados, conquistados, impucstos a través de luchas seculares del puchlo (en las que no sólo han jugado un papel impor- 
tante los esiratos desfavorecidos, sino también la pequeña burguesía). Allá donde solamente han sido importados, han sido casi siempre débiles y frágiles (consideremos el caso de los países de América Latina o Japón). Además, esios derechos y libertades no se corresponden con el "espíritu" del capilalismo; este último exige más bien el one hest way de Taylor o la "jaula de hierro" de Max Weber. Igualmente falsa es la idea de que representarian la premisa política de la concurrencia en el mercado económico, pues ésta es solamente un momento, ni espontáneo (Polanyi) ni permanente del capitalismo, cuya lendencia interna conduce al monopolio, al oligopolio o a las coaliciones entre capilalistas. Y tampoco constituyen una precondición para el desarrollo del capilalismo (consideremos de nuevo el ejemplo de Japón). Por fin, y sobre lodo, esios derechos y libertades no son en absoluto "formales": por el contrario, corresponden a rasgos de vital necesidad en todo régimen democrálico. Sin embargo, son parciales y, como se ha dicho antes, esencialmente defensivos. Tambien la cualificacion de "negativos" (I. Berlin) es inadecuada. El derecho a reunirse, a manilestarse, a publicar un periódico o un libro no es "negalivo": su ejercicio constiluye una componente de la vida social y polílica y puede tener y liene necesariamente ef ectos importantes sobre ella. Otra cosa es que pueda ser obstaculizado por las condiciones efeclivas o, como ocurre hoy en los páses ricos, que pueda ser reducido a un papel más o menos fúlil a causa del marchitamiento polílico general. Precisamente, una parte principal de la lucha por la democracia apunta hacia la instauración de las condiciones reales que permilan a lodos el ejercicio efectivo de estos derechos. Recíprocamente, esta lalaz denuncia del carácter "formal" de los derechos y liberlades "burguesas" ha lenido resullados calasirificos, sirviendo de trampolín a la instauración del totalitarismo leninista y dando cobertura a su continuación a través del estalinismo.

Estas libertades y derechos no son, por tanto, "formales": son parciales y, en la realidad social efectiva, esencialmente defensivos. Por la misma razón, no son "negativos". La expresión de I. Berlin pertenece al contexto y al patrimonio histórico al que he hecho referencia al principio. Corresponde a la actitud subyacente, cuasipermanente, de las sociedades y poblaciones europeals (no sólo de éstas, pero de ellas estamos hablando aqui) respecto al poder. Precisamente cuando se ha roto, al menos en parte, el imaginario milenario de la realeza del derecho divino (ratificado y reforzado por el cristianismo, "todo poder viene de Dios"), sigue subsistiendo con no menos intensidad la representacion del poder como extraño a la sociedad, frente a ella y opuesio a ella. El poder son "ellos" (us and them, sigue diciéndose en inglés), nos es hostil como norma y se trata de contenerlo dentro de sus límites y de defendernos ante él. Solamente en las épocas revolucionarias, en la Nueva Inglaterra o en Francia, la frase we the people [nosotros, el pueblol o el término Nación, adquicren un sentido polílico y se declara que la soberanía pertenece a la nación, frase que será rápidamente vaciada de su contenido a través de la "representación". En semejanle contexto,

Lo democrocio como procedimiento y como régimen 
se comprende que los derechos y libertades ha ser considerados como insirumentos de defensal contra un Estado omnipotente y esencialmente extraio.

I. Berlin opone a estas libertades "negativas", las únicas aceptables en su opinión, una idea de la libertad "posiliva" emparentada con la concepción democrática antigua (griega) según la cual todoss los ciudadanos deben lomar parle del poder. Esta idea, según ese autor, sería polencialmente autorilaria pues presupondría la imposición de una concepción positiva, y colectivamente (políticamente) determinada, del Bien comin o (lel bien vivir. Muchass son las grietas en ese razonamiento. La libertad electiva (mejor (jue "posiliva") de todos mediante la participación en el poder no implica una concepción del Bien comin mais de lo que lo haga cualquier decisión legislativa, de gobierno o judicial, tomada por "representanles", ministros o jueces togados. Como ya se ha dicho, nunca puede ejercerse, por ejemplo, un sistema de derecho (jue sea complelamente (o esencialmente) Werefrei, neutro en cuanto a valores. Ha reconocimiento de una esfera libre de "aclividad privada" — cualesquiera que sean sus limiles- procede asimismo de la afirmación de un valor sustantivo y que prelencle lener validez. universal: es bueno para todos (jue los indivicluos se muevan libremente dentro de la esfera de la actividad privada reconocicla y garantizacla por la ley. Ia delimitación de estas esferas, el conteniclo de las eventuales sanciones en caso de ser transgredidas por otras, (lele necesariamente recurrir a algo distinto (jue una concepción formal de la ley, como sería fácil clemostrar a propósito de cualquier sislema de derecho positivo (para poner un ejemplo, es imposible establecer una graduación de la gravedad de los delies y de las penas sin establecer un "parangón" entre el valor de la vida, de la liberlacl - la prision-- el dinero, elc.)

Implicila en la argumentación de Berlin hay otra confusión: entre el Bien común y la felicidad. El fin de la polílica no es la felicidacl, coue solamente puede ser un asuntos privado ${ }^{15}$, es la liberlad y la autonomia individual y colecliva. Pero no puede ser solamente la autonomía, porcue entonces se recaeria de nuevo en el formalismo kantiano y hajo lodas las legílimas críticas de las (jue ha sido objelo desde su origen. Como he dicho en otro lugar"t, (jueremos la liberlad al mismo tiempo por sí misma y para hacer alguna cosa, para pocler hacer cosals. Y bien, una inmensa parle de esas cosas no estamos en condiciones de hacerlas solos. o bien dependen fuertemente de la instilución global de la sociedad, y. generalmente, las dos circunstancias se verifican simullancamente. Iso implica necesariamente una concepción, aunque sea mínima, del Bien comin.

Es cierto, como he recordado al comienzo del texto, que Berlin no ha creado esta confusión, limitándose a comparlirla. Ella proviene de lejos, y es tanto más necesario disiparla. La distinción a restablecer es antigua (y su olvido por los teóricos modernos tiene aún menos excusa). Se trala (le la distinción entre la felicidad, hecho estrictamente privado, y el Bien común (o la huena vida), im- 
pensable sin referirse al campo público y al campo público/público (cl poder). Es la misma, en términos diferentes pero que enriquecen la discusión, que la distinción entre eudaimonia, la felicidad, que no es eph hemin. no depende de nosotros, y el eu zein, el bien vivir, que, en gran parte, depende de nosotros, individual y colectivamente (ya que depende tanto de nuestros actos como de los que nos circundan, y, en un nivel a la vez más abstraclo y más profundo, de las instituciones de la sociedad). Se pueden casar ambas distinciones, alirmando que la realización del bien comín es la condición del buen vivir.

¿Pero qué determina o define el buen vivir? Ouizá una las razones principales de la confusión que rodea la pregunla es que la filosofia ha predendido poder dar esila determinación o definición. lesio hal ocurrido porcue el papel de pensiadores de la política ha sido jugado principalmente por filosolos, y éstos, por profesión, querrian determinar de una vez por todas una "felicidad" y un "bien común", y, si es posible, hacerles coincidir. In el marco del pensamiento heredado, esta determinación tenía que ser universal, válida para lodo liempo y lugar, y, al mismo liempo, establecida de algún modo a proori. esta es la raíz del "error" de la mayor parle de los filossolos cue han escribo sobre polilical y del error simétrico de aquellos otros que, para evilar lo absurdo de las consecuencias de esta solución - Platon, por ejemplo, gue legislaba sobre modos musicales permitidos y prohibidos para loda "buena" sociedad- se han reducido a rechazar la pregunta misma, ahandonándola al libre arbilrio de calda uno. No puede haber lilossofia que det ina para lodos gué es la felicidad, y menos anin cue la quiera imponer a lravés de decisiones polílicas. La felicidad peranenece a la esfera privada y privada/pública. No pertenece a la esfera pública/priblica en cuanto lal. La democracia, como régimen de la liberlad, excluye cierlamente cuue una "lelicidad" pueda ser presentada, en si misma o en sus "medios", como politicamente obligatoria. Se puede anadir: ninguna filosolia en ningin momen10 puede delinir un "bien común" sustantivo, y ninguna political puede esperar para acluar a que la filosofia haya establecido semejante bien commin".

Pero las preguntas (jue se plantean en la esfera puiblica/publica (a la legislacion, al gobierno) no pueden sicjuiera ser disculidas sin una visicin del bien común. Lil bien común es, al mismo liempo, una condicion de la felicidad individual y también atañe a las obras y trabiajos que la sociedad leliz o no querria ver realizadas.

Esio no afecta sólo al régimen democrálico. Lil anílisis ontológico muesira que ninguna sociedad puede existir sin una delinicion, mis o menos segura, de los valores sustantivos compartidos, de los hienes sociales comunes (los public goods de los economistas sölo son una parle de ellos). Esilos valores representan una parle esencial de las significaciones imaginarias sociales establecidas. Delinen el empuje de cada sociedad; suministran normas y crilerios no formalmente instituidos (por ejemplo, los griegos distinguian entre dikaion y kalom); final-

Lo democrocio como procedimiento y como régimen 
mente, sostienen el mandato institucional explícito. Un régimen político no puede ser totalmente agnóstico en cuanto a valores (o morales, o éticas). Por ejemplo, el derecho no puede hacer otra cosa que expresar una concepción común (o dominante, bien o mal aceptada) del "mínimo moral" implicado en la vida en sociedad.

Pero estos valores y esta moralidad son creación colectiva anónima y "espontánea". Pueden ser modificados hajo la influencia de una acción consciente y deliberada, pero es necesario que esta última incida sobre otros estratos del ser histórico-social, no solamente por los afectados por la acción política explícita. En todo caso, la cuestión del hien común pertenece al campo del hacer histórico-social, no al de la teoría. La concepción sustancial del bien común, en cualquier caso, es creación histórico-social, y, evidentemente, se encuentra tras todo derecho y todo procedimiento. Esto no conduce al simple "relativismo", cuando se vive en un régimen dernocrático en el que la interrogación queda abierta efectivamente y de forma permanente, lo que presupone la creación social de individuos capaces de interrogarse efectivamente. Aquí encontramos, al menos, una componente del bien común democrático, sustantivo y no relativo: la ciudad dehe hacer todo lo posible para ayudar a los ciudadanos a llegar a ser efectivamente autónomos. Esa es, ante todo, una condición de su existencia en tanto que ciudad democrática: una ciudad está hecha de ciudadanos, y ciudadano es aquel que es "capaz de gohernar y de ser gohernando" (Aristóteles). Pero es tambićn, como ya he dicho, una condición positiva del hien vivir de cada uno, dependiente de la "cualidad" de los otros. Y la realización de este objetivo —ayudar a los ciudadanos para que lleguen a ser autónomos, la paideia en la acepción más fucrte y profunda del término- es imposible sin decisiones polílicas sustantivas, que, por otra parte, no pueden dejar de ser tomadas en cualquier lipo de régimen y en cualquier caso.

La democracia como régimen es, por lanto, al mismo tiempo, el régimen que intenta realizar, tanto como resulta posible, la autonomía individual y colectiva, y el bien común tal como es concebido por la colectividad considerada.

El ser humano singular reabsorhido en "su" colectividad, en la que, evidentemente, se encuentra por azar (el azar de su nacimiento en determinado lugar y determinado momento), por un lado, y por otro, esic mismo ser separado de toda colectividad, contemplando la sociedad a distancia y procurando ilusoriamente considerarla al mismo tiempo como un artefacto y como un mal necesario, son dos consecuencias del mismo desconocimiento, que se pone de manifiesto en dos niveles:

(a) Como desconocimiento de lo que son el ser humano y la sociedad, de lo mostrado por el análisis de la humanización del ser humano como socialización y la "encarnación”-materialización de lo social en el individuo; 
(b) Como desconocimiento de lo que es la política en cuanto creación ontológica en general —creación de un tipo de ser que se da explícilamente, aunque en parte, las leyes de su propia existencia y, al mismo tiempo, en cuanto proyecto de autonomía individual y colectiva.

La politica democrática es, en los hechos, la actividad que intenta reducir, tanto como sea posible, el carácter contingente de nuestra existencia históricosocial en sus determinaciones sustantivas. Ni la política democrática en los hechos, ni la filosofía en la idea, pueden suprimir aquello que, desde el punto de vista del ser humano singular y de la humanidad en general, aparece como el azar radical (que lleidegger veía en parte, pero restringía exlrañamente al ser humano singular, bajo el título de (ieworfenheit, abandono o "estar-arrojado"), haciendo así que haya un forma de ser, que esto se manifieste como mundo, que dentro de este mundo haya una forma de vida, y en estal vida haya una especie humana, en esta especic una cierla lormación hislórico-social y en esla formalción, en tal lugar y momento, florezca en un vientre entre millones, aparezca este pedazo de carne que berrea, y no otro. Pero ambas, polílical democrílica y filosolía, praxis y pensamienlo, pueden ayudarnos a limitar, o mejor a Iranslormar, la parte enorme de contingencia que delermina nuestra vida a través de la libre acción. Sería ilusorio alirmar que ellas ayudan a "asumir libremente" las circunstancias que no hemos escogido y que no podremos nuncal escoger. I:l hecho mismo de que un lílósolo pueda pensar y escribir que la liberlad es la conciencia de la necesidad

(Independientemente de toda consideración sustantiva sobre el sentido de esa frase) está condicionado por una miriada no numerable de olros hechos contingentes. La simple conciencia de la mezcolanza inlinita de contingencia y necesidad - de contingencia necesaria y de necesidad en último análisis contingente que condiciona lo que somos, lo que hacemos, lo que pensamos, estí bien alcjada de ser libertad. Pero es condición de esta liberlad, condición requerida para emprender lúcidamente las acciones que pueden conducirnos a la autonomia efectiva tanto en el plano individual como en el plano polílico.

\section{Notas}

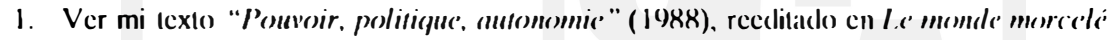
I.es (arrefours du labyrinthe III. Paris. I.e Scuil, 1990), pp. 117-124.

2. Sanciones legitimats respecto al derecho positivo, no en absoluto.

3. Para Ilahermas, ver su último Irabajo, "Three Models of I)emocracy", en ('omstellations, Vol. I, N2 I, abril 1994, pp. I-10.

4. Términos de la dedicaltoria de la ('ritica de la razón pura, Königsherg. 29 de marzo de 1781, al Freiherr Van 7,edlitz, ministro de eslado del rey de Prusia.

5. Ver mi "les.s intellectuels e'l l'histoire" (1987), recditido en L. Momde morcele, op. cil., pp. I0.3-III.

6. Ver mi texto (1981), reeditado en Domaines de l'homme -tes Carrefours du labyrinthe, Paris, I.c Scuil, I98h. pp.307-324.

Lo democrocio como procedimiento y como régimen 
7. Términos que empleo simbólicamente (y por abuso del lenguaje). La Asamblea ateniense no ejercitaba el poder judicial y no hacia más que supervisar al "cjecutivo" en el sentido que se da a lal lérmino (administración).

8. Ver mi "Fait et a faire", en Autonomic et auto-trasformation de la socicté. la philosophie militante de Cornelius (astoriadis, Ginebra-Paris, Droz, 1989), en particular pp.50)(-513.

9. Aquello que en el lenguaje filosófico y constitucionalista moderno se denomina "cjecutivo", se escinde en dos: Poder (o funciones) de gobierno y poder (o funciones) administrativo. El "Gohicrno", en cuanto gohierno, no "cjecula” las leyes, esencialmente actúa (gohierna) en el cuadro de las leyes. La administracioin, en la medida en que no puede ser "mecanizada" enteramente, no puede lampoco escapar a las cuestiones de interpretición, como las evocidas en el lexio.

10. Ver mi análisis de las ideas de Aristóteles sobre ese tema, en "Vale'ur, égalité, justice. politique: de Marx à Aristote et d'Aristote a nous" (197.5), recditado en I.es Carrefours du lahyrinthe, Paris, Le Seuil, 1978, especialmente pp 274-306.

11. No se trallit evidentemente de las intenciones "históricamente eslablecidlas", sino de la inserción necesaria -y problemática- de lodal cliusula parlicular en el sistema juridico en su conjunto, que evolucional continuamente.

12. Ver mi texio cilido en la nola 10 .

13. Desde muchos siglos antes de la Revolucion francesi, la Monarquia, alosolula o "ilusirada" realizaba en la mayor parte de los países de Liuropal ()ecidental un "Lsilado de ley". "Aqui hay jueces en Posidlam". replicabal el molinero prusiano a liederico el Cirande.

14. Poco más o menos asi lo justificaba Aristobleles en la Comstitución de los anc'nic'nse's, $\mathrm{XLI}$

15. Ver "Racines subjerives du projet révolutionnaire" en la primera parte (19)(19-6.5) de mi libro L 'institution imaginaire de la Socictí. Paris, Le Scuil. 197.5, pp. 126-127.

16. Ver mi tex10 "La polis grecque el la créalion de la democralie" (1982), recelitado en Domaines de l'homme, op.cit., en parlicular, pp.287-296.

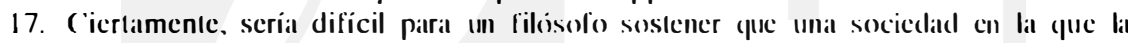

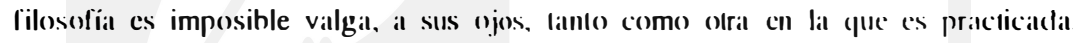
Pero, a falta de una aclaración suplementaria (y largai) del conteniclo del termino libsolía, esto no define políticamente un lipo de sociedacl. Ilat halhido unia, o, al menos, una cierta libosolía en la India y en ( hina (por no halhlar del lslam y de la Europa medieval). Pero de ahi no se derival que una socicelad de calsials o con un mandarinalo equivalga politicamente a una sociedald democralical. 